\section{Severe hypoxia following video capsule endoscopy}

\author{
Adil T. Degani, Caralee J. Forseen, \\ Albert S.Y. Chang \\ Medical College of Georgia, GA, USA
}

\section{Abstract}

Video capsule endoscopy is generally associated with gastrointestinal complications, but there have been few instances of asymptomatic aspiration. We present a 74-year-old male being evaluated for gastrointestinal bleed. A video capsule was deployed with no acute respiratory symptoms. However, after airway intubation for emergent gastrointestinal surgery, he developed profound hypoxia. The video capsule was found to be completely occluding his left main stem bronchus. Due to a significantly surgically altered airway secondary to previous head and neck carcinoma and the capsule's difficult size and shape, the capsule was dislodged only through the use of a Fogarty catheter with eventual removal from the oropharynx using forceps.

\section{Introduction}

The source of gastrointestinal (GI) hemorrhage often cannot be verified through traditional endoscopy. Video capsule endoscopy provides clinicians with an additional tool to diagnose obscure GI bleeds. Contraindications to capsule endoscopy include dysphagia and GI obstruction. ${ }^{1}$ As well, the capsule can also be placed endoscopically. The most common complications include capsule retention and the potential for GI injury. ${ }^{2}$ We present a rare pulmonary complication of video capsule endoscopy.

\section{Case Report}

A 74-year-old white male was transferred from an outside hospital secondary to a GI bleed. Previous endoscopic evaluation was non-diagnostic. His past medical history was pertinent for squamous cell carcinoma of the right neck requiring surgical resection. On physical examination, his vital signs were stable. He had a surgically altered right neck base, but well healed surgical scars. He tolerated a soft mechanical diet and swallowed medications. His abdomen was soft, non-tender and no stool or blood was found on rectal exam. His hemoglobin was $8.8 \mathrm{mg} / \mathrm{dL}$, whereas one month earlier it had been $13 \mathrm{mg} / \mathrm{dL}$.

Due to his history of mild dysphagia, the GI service attempted endoscopic video capsule placement. Unfortunately, the capsule and the deployment casing became dislodged in the hypopharynx and were unable to be retrieved. It was thought that the patient had reflexively swallowed the capsule. He had no evidence of respiratory distress or cough and his oxygen saturation was greater than $90 \%$ on room air. A post procedure x-ray was interpreted as the capsule being located in the esophagus.

The next day, repeat EGD found an active duodenal bleed. He was taken emergently to the operating room, intubated and placed on mechanical ventilation. He tolerated duodenal ulcer repair, but became severely hypoxic. Arterial blood gas performed on 100\% oxygen revealed a $\mathrm{PaO}_{2}$ of $47 \mathrm{mmHg}$. The patient was hemodynamically stable, and per anesthesia notes, he had equal bilateral breath sounds. A chest x-ray (Figure 1) was obtained and pulmonary was emergently consulted.

Bronchoscopy revealed complete obstruction of the left main stem bronchus by the video capsule (Figure 2). Due to its size, shape and location, the capsule could not be removed with traditional therapies including forceps, wire basket or a roth net. Instead, a Fogarty catheter was passed distal to the pill, inflated and pulled back to retract the capsule to the trachea (Figure 3) and eventually to the hypopharynx where it was removed via forceps. He was then safely transferred to the ICU without further sequelae.

Review of the patient's pill cam video showed that the capsule went directly to the left main stem bronchus where it became lodged at the twelfth minute and stayed for the remaining $8 \mathrm{~h}$ of video.

\section{Discussion}

This case presents a rare occurrence of video capsule endoscopy aspiration, made symptomatic after intubation. We hypothesize that the positive pressure from mechanical ventilation forced the pill distally, completely occluding the left main stem bronchus. This suggests that non-emergent intubation in large foreign body aspiration should potentially be avoided. A large, round, foreign object in a severely surgically altered airway also complicated our case. As a result, we were unable to use rigid bronchoscopy or other traditional retrieval methods and were forced to rely on balloon catheters. Other retrieval options include the use of cryoprobes which can be cold-adhered to foreign objects ${ }^{3}$ as well as surgical removal of foreign objects as a means of last resort.

There have been only seventeen previous
Correspondence: Adil T Degani, Medical College of Georgia 1120 15th Street Augusta, GA 30912, USA. Mob: 703.597.6717.

E-mail: atdegani@hotmail.com

Key words: bronchoscopy, video capsule, aspiration.

Contributions: the authors contributed equally.

Conflict of interest: the authors report no conflicts of interest.

Received for publication: 27 August 2011.

Revision received: 25 September 2011.

Accepted for publication: 28 September 2011.

This work is licensed under a Creative Commons Attribution NonCommercial 3.0 License (CC BYNC 3.0).

(C) Copyright A.T. Degani et al., 2011

Licensee PAGEPress, Italy

Chest Disease Reports 2011; 1:e12

doi:10.4081/cdr.2011.e12

cases of pill cam aspiration mentioned in the literature. ${ }^{1,4-19}$ These patients had only mild respiratory symptoms, such as cough or wheeze, and none had the severe hypoxia observed in our patient. Indeed, 5 of the patients were completely asymptomatic ${ }^{1,9,13,15,16}$ Only 3 previous patients aspirated the capsule to the left. ${ }^{10,16,17}$ Factors favoring foreign body aspiration to the right include the angle and increased diameter of the right main stem bronchus as well as increased airflow to the right hemithorax. Our patient was in the left lateral decubitus position during the initial endoscopy, favoring aspiration to this side. Approximately half the patients spontaneously ejected the capsule, ${ }^{1,5,7,9,11,12,14,15,19}$ while the others required either bronchoscopic or endoscopic intervention., $4,6,8,10,13,16-18$

Capsule endoscopy is used routinely for identification of obscure GI bleed. However, clinical complications are rare. ${ }^{1}$ As such, the few case reports referenced in this article and experience with aspiration of other foreign bodies are the only source for clinical recommendations. In cases where there is clear aspiration or loss, standard radiography should easily identify the location of the capsule. This would certainly be the preferred method should surgery or pulmonology be consulted. In situations where the patient is not clinically stable for transport, video images themselves can be downloaded within minutes..$^{20}$ of the few cases we cited, most resolved without intervention. Ultimately, if the location of the capsule is unknown, direct visualization is necessary. If there is clear aspiration, regardless of symptomatology, the capsule should be 


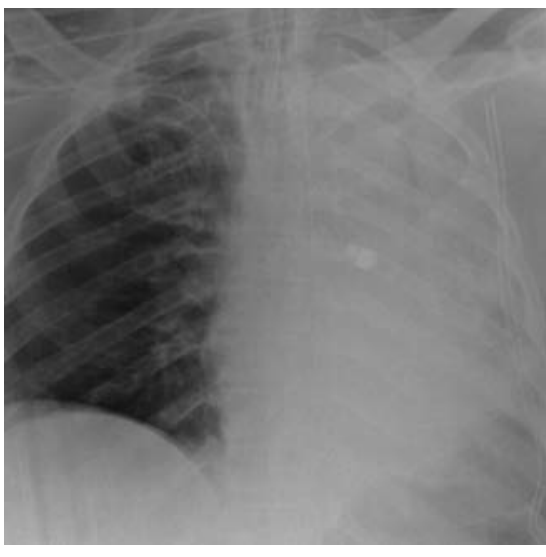

Figure 1. Chest $x$-ray showing complete opacification of the left hemi-thorax and the video capsule in the left main stem bronchus.

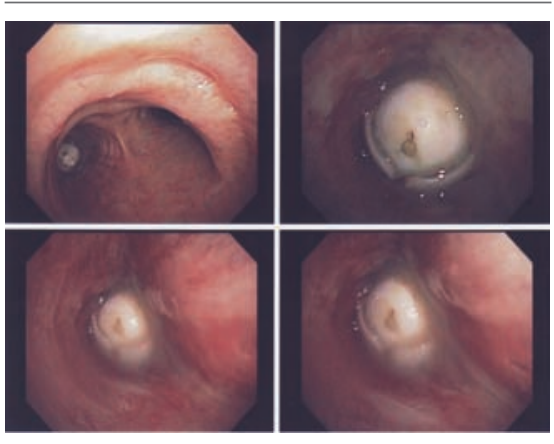

Figure 2. Bronchoscopic view of the carina and occluded left main stem bronchus by the video capsule.

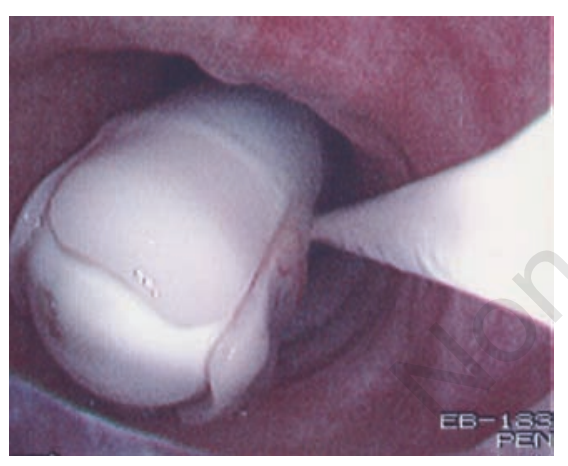

Figure 3. Bronchoscopic view of the trachea with Fogarty catheter being used to retract the video capsule. urgently retrieved.

In conclusion, we present a case of severe hypoxia following video capsule endoscopy. Use of direct endoscopic placement of the video capsule should help to prevent this complication in the future, but not always, as this case demonstrates. A high index of suspicion for aspiration and radiographic or endoscopic confirmation is necessary when capsule delivery is difficult or patients become symptomatic. We hope to increase awareness of this rare, but potentially fatal pulmonary complication as well as to describe other methods by which to remove difficult foreign objects.

\section{References}

1. Rondonotti E, Herrerias JM, Pennazio M, et al. Complications, limitations, and failures of capsule endoscopy: a review of 733 cases. Gastrointest Endosc 2005;62:712-6.

2. Mazzarolo S, Brady P. Small bowel capsule endoscopy: a systematic review. South Med J 2007;100:274-80.

3. Swanson KL. Airway foreign bodies: what's new? Semin Respir Crit Care Med 2004;25: 405-11.

4. Fleischer DE, Heigh RI, Nguyen CC, et al. Videocapsule impaction at the cricopharyngeus: a first report of this complication and its successful resolution. Gastrointest Endosc 2003;57:427-8.

5. Schneider AR, Hoepffner N, Rösch W, Caspary WF. Aspiration of an M2A capsule. Endoscopy 2003;35:713.

6. Buchkremer F, Herrmann T, Stremmel W. Mild respiratory distress after wireless capsule endoscopy. Gut 2004;53:472.

7. Sinn I, Neef B, Andus T. Aspiration of a capsule endoscope. Gastrointest Endosc 2004;59:926-7.

8. Tabib S, Fuller C, Daniels J, Lo SK. Asymptomatic aspiration of a capsule endoscope. Gastrointest Endosc 2004;60: 845-8.

9. Nathan SR, Biernat L. Aspiration - an important complication of small-bowel video capsule endoscopy. Endoscopy
2007;39 Suppl 1:E343.

10. Sepehr A, Albers GC, Armstrong WB. Aspiration of a capsule endoscope and description of a unique retrieval technique. Otolaryngol Head Neck Surg 2007;137:965-6.

11. Shiff AD, Leighton JA, Heigh RI. Pulmonary aspiration of a capsule endoscope. Am J Gastroenterol 2007;102:215-6.

12. Bredenoord AJ, Stolk MF, Al-toma A. Unintentional video capsule bronchoscopy. Eur J Gastroenterol Hepatol 2009;21:593.

13. Guy T, Jouneau S, D'Halluin P, Lena H. Asymptomatic bronchial aspiration of a video capsule. Interact Cardiovasc Thorac Surg 2009;8:568-70.

14. Koulaouzaidis A, Pendelbury J, Douglas S, Plevris JN. Aspiration of video capsule: rare but potentially life-threatening complications to include in your consent form. Am J Gastroenterol 2009;104:1602-3.

15. Leeds JS, Chew TS, Sidhu R, et al. Asymptomatic bronchial aspiration and retention of a capsule endoscope. Gastrointest Endosc 2009;69:561-2.

16. Choi HS, Kim JO, Kim HG, et al. A case of asymptomatic aspiration of a capsule endoscope with a successful resolution. Gut Liver 2010;4:114-6.

17. Depriest K, Wahla AS, Blair R, et al. Capsule endoscopy removal through flexible bronchoscopy. Respiration 2010;79: 421-4.

18. Kurtz LE, Devito B, Sultan K. Electronic image of the month. Small bowel video capsule aspiration with bronchoscopicassisted extraction. Clin Gastroenterol Hepatol 2010;8:e37-8.

19. Lucendo AJ, González-Castillo S, Fernández-Fuente M, De Rezende LC. Tracheal Aspiration of a Capsule Endoscope: A New Case Report and Literature Compilation of an Increasingly Reported Complication. Dig Dis Sci 2011; 56:2758-62.

20. Hollerbach S, Kraus K, Willert J, et al. Endoscopically assisted video capsule endoscopy of the small bowel in patients with functional gastric outlet obstruction. Endoscopy 2003;35:226-9. 